\title{
Bioinspired Surfaces Against Bacterial Infections
}

\author{
José Gomes ${ }^{\S}$, Alexander Grunau, Adrien K. Lawrence, Leo Eberl, and Karl Gademann
}

§SCS-DSM Award for best poster presentation

\begin{abstract}
Bioactive surfaces that can prevent bacterial infections are of great interest since device-related infections represent an emerging and major threat to our health-care system. For that purpose, dopamine and its derivatives have been shown to provide an exceptionally facile method for the immobilization of bioactive compounds on metal oxide surfaces through an operationally simple dip-and-rinse procedure. Based on this method, three different coating strategies for the assembly of antifouling, antibacterial, and quorum sensing modulating surfaces have been established. The anachelin chromophore and nitro-dopamine proved to be very suitable anchoring moieties as they possess better oxidative stability and binding efficiency compared to dopamine itself. Furthermore, adsorbed bioactive hybrids were shown to be stable and recycling of the surfaces could be achieved. These examples clearly demonstrate the efficiency of this approach for the production of active surfaces, such as in biomedical devices.
\end{abstract}

Keywords: Antibacterial · Antifouling · Catechols · Mussel adhesive proteins · Quorum sensing

\section{Introduction}

Health care-associated infections remain a devastating problem for patients worldwide. Among these, bacterial infections of implant materials and devices, such as catheters and stents, pose a major threat to the quality of life of those affected..$^{[1,2]}$ Recent studies show that about half of nosocomial infections are caused by such device-associated infections. ${ }^{[3]}$ Improved procedures in sterilization, proper hygiene, and operating techniques have much reduced the likeliness of an early stage infection, ${ }^{[4]}$ however, the infection rates that occur weeks and months after surgery have barely decreased. Such incidences mostly occur due to the ability of bacteria to attach to biomedical implants and thereby trigger infections in the host, which are often not detected at an early stage. In most cases, the infections cannot be diagnosed before damage has been caused to tissue and the host organism. Upon adherence to the surface, microorganisms grow and accumulate

\footnotetext{
*Correspondence: J. Gomes

University of Basel

Department of Chemistry

St. Johanns-Ring 19

$\mathrm{CH}-4056$ Basel

Tel.: +41612671129

E-mail: jose.gomes@unibas.ch
}

in multilayered cell clusters, thereby forming biofilms, which is considered to be the first step in nosocomial infections. ${ }^{[5,6]}$ In this state, the developed bacterial biofilms protect themselves against the host's innate immune system and even antibiotics by generating an exocellular polysaccharide matrix. A direct systematic treatment with antibiotics is difficult due to reduced susceptibility of adherent bacteria, leading to a several orders of magnitude decrease in antibiotic efficacy. ${ }^{[7,8]}$ Furthermore, the rise of resistant bacterial strains constitutes an additional challenge to be overcome. ${ }^{[7-11]}$ As a result, current successful treatment usually requires surgical replacement of the infected devices, combined with prolonged intravenous and oral therapy with antibiotics. ${ }^{[12]}$ These complications not only result in additional costs to the health care system, but most importantly, also lead to suffering of the patients and occasionally to their death. Currently, about $30 \%$ of the hospitals in the US are using antimicrobial catheters to prevent hospitalacquired urinary tract infections. ${ }^{[13]}$ The release of silver ions is most likely preventing the infection in these cases. However, the usage of silver-containing medical devices must be undertaken with caution since silver has demonstrated a certain level of toxicity to mammalian cells. ${ }^{[14]}$ Therefore, bioactive surfaces that can prevent infections of implants are currently the focus of many research groups. Various techniques have been established for the coating of biomedical devices, including biopassive and bioactive surfaces, with either a cova-

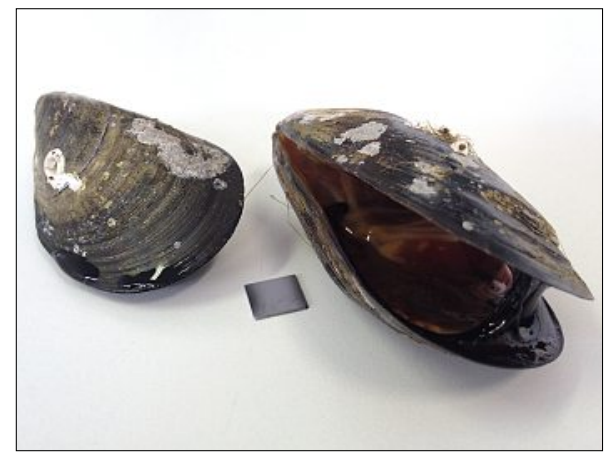

Fig. 1. Mussels secrete proteins for adherence to surfaces, such as $\mathrm{TiO}_{2}$.

lently attached bioactive moiety or one that is released into the surrounding periphery. Despite of the elegance of these immobilization techniques, some drawbacks have to be overcome, such as limited stability or range of substrate materials.

\section{Bioinspired Adhesion}

A particular challenge consists in the development of coating agents that can strongly bind active compounds to surfaces. Recently, catechols have been presented as promising alternatives for the mild functionalization of metal oxide surfaces. ${ }^{[15-21]}$ The development of such anchors has been inspired by the adhesive properties of marine and freshwater mussels to all kind of surfaces (Fig. 1). Mussels secrete adhesion proteins (MAPs), which serve as anchors and are responsible for the strong 
wet adhesion on surfaces. ${ }^{[22,23]}$ MAPs have been shown to contain up to $27 \%$ of the posttranslationally modified amino acid 3,4-dihydroxyphenyl-L-alanine (DOPA), which is the key constituent for adhesion (Fig. 2). The usefulness of catechols as anchoring groups for the functionalization of surfaces has been extensively studied and many different bioactive applications have been established so far. ${ }^{[21,24]}$ Even further, many different catechol derivatives have been studied and compared for their binding capacities, from which some of them are shown in Fig. 2. Even though dopamine and L-DOPA have been shown to be powerful anchoring groups, they can easily be oxidized and polymerize, rendering their handling and storage inconvenient. ${ }^{[25,26]}$ More stable catechol moieties can be found in nature, such as the anachelin chromophore, a cyanobacterial siderophore. ${ }^{[27,28]}$ In marine environments, iron can become a growth-limiting nutrient since its bioavailability is very low. That is why some bacteria secrete anachelin into their extracellular surroundings to bind and sequester iron. ${ }^{[29]}$ The quaternary aromatic ammonium substituent present renders this compound oxidatively more stable and it was shown to exhibit superior binding properties compared to dopamine. A purely chemical derivative that also demonstrates good binding properties is nitrodopamine. ${ }^{[25]}$ Even though nitro-dopamine showed slightly weaker binding properties, it is synthetically more easily accessible as it can be prepared in a single step from the commercially available and cheap dopamine, in contrast to the anachelin chromophore, which requires multiple synthetic steps, involving heavy-metal-based ${ }^{[30,31]}$ or enzymatic ${ }^{[32,33]}$ conversions. Therefore, we have been exploring these two anchor moieties for the functionalization of titanium dioxide $\left(\mathrm{TiO}_{2}\right)$ surfaces. We chose to utilize this metal oxide due to its biocompatibility and frequent application in the field of medical devices. In this highlight article, an overview of our recent development in the field of catechol-based bioactive surfaces against bacterial infections is given, especially for the production of antifouling, antibacterial, and quorum sensing modulating surfaces.

\section{Antifouling Coating}

The unspecific adsorption of proteins and microorganisms onto surfaces upon their immersion in biological fluids has been defined as biofouling. ${ }^{[34]}$ Antifouling materials have been the subject of much interest and extensive research in recent years. ${ }^{[35]}$ The adhesion of bacteria to such biopassive surfaces can be prevented by decreasing the direct contact between them<smiles>NCCc1ccc(O)c(O)c1</smiles>

dopamine<smiles>NCCc1cc(O)c(O)cc1[N+](=O)[O-]</smiles>

nitro-dopamine<smiles>C[N+]1(C)C[C@@H](N)Cc2cc(O)c(O)cc21</smiles>

anachelin chromophore<smiles>N[C](Cc1ccc(O)c(O)c1)C(=O)O</smiles>

\section{L-DOPA}

and the surface. For this purpose, various techniques have been adapted for the immobilization of poly(ethylene glycol) (PEG) on different surfaces. ${ }^{[36,37]}$ Such PEG-coated biomaterials were shown to drastically decrease the amount of adsorbed protein due to the formation of an interfacial layer without directly interfering with the microorganisms. This approach was expanded by the introduction of catechol moieties as anchoring groups. ${ }^{[26-28]}$ The advantage of such a system is the facile functionalization of the surface, which can be achieved by a simple dip-and-rinse procedure in aqueous solution under cloud point conditions. ${ }^{[25,26,38,39]}$ Therefore, the binding properties of the anachelin chromophore were conjugated to the antifouling nature of PEG (Fig. 3, top left). ${ }^{[26]}$ Upon adsorption of the resulting PEG-anachelin conjugate onto a $\mathrm{TiO}_{2}$ plate, a very large reduction of the protein adlayer thickness of over $95 \%$ was observed upon exposure to full human serum in comparison to untreated control surfaces. This strategy enabled the formation of a stable, protein-resistant adlayer. The anchor moiety not only displayed excellent binding strength, but also particularly oxidative stability when compared to other dopamine derivatives reported in the literature. Furthermore, the readily available nitro-dopamine-PEG conjugate (Fig. 3, top right) resulted in comparable binding properties and oxidative stability. It is noteworthy that even though biofouling on biomedical devices can be prevented by this approach, it has the disadvantage that it cannot kill bacteria upon exposure.

\section{Antibacterial Coating}

An appealing strategy to overcome this problem is the incorporation or absorption of antimicrobial agents onto or into the implant surface. Such antibiotic surfaces have the ability to actively kill bacteria upon contact or by slow release of the active compounds into the local tissue.[40] The immobilization of antibiotics usually requires multiple chemical steps on the solid surface and scale-up of these processes can be problematic. In order to circum-

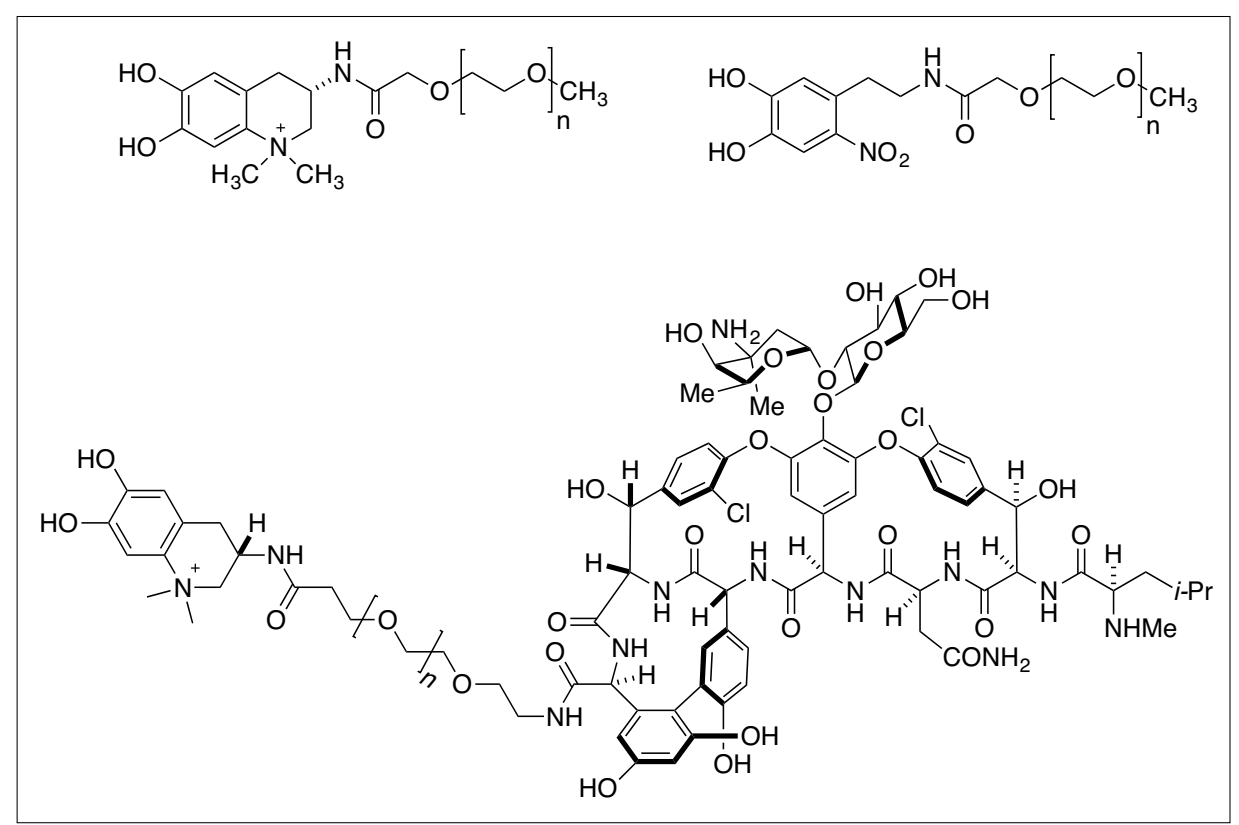

Fig. 3. Various antifouling and antibacterial coating agents. 
vent this problem, preparation of coated implant surfaces via simple dip-and-rinse procedures represents a far simpler method of choice. Therefore, vancomycin, a wellstudied antibiotic agent frequently used against bacterial infections, was chemically linked to the anachelin chromophore via a PEG linker (Fig. 3, bottom). ${ }^{[28]}$ This natural product hybrid delivers three different properties: strong binding to the $\mathrm{TiO}_{2}$ surface through the anachelin chromophore moiety, prevention of bacterial adhesion onto the surface through the PEG linker, and antiseptic properties against Grampositive bacteria through antibiotic vancomycin. The resulting antimicrobial hybrids were immobilized onto a $\mathrm{TiO}_{2}$ surface via our established and simple dip-coating process. The functionalized surfaces were shown to possess antibacterial activity against Bacillus subtilis. Furthermore, the obtained functionalized surfaces proved to be recyclable, as they could be washed out by rinsing with water and reused without loss in antimicrobial activity. This hybrid strategy could also be applied to other antimicrobial agents. Even further, the combination of different antibiotics on biomedical surfaces could be achieved, thereby broadening the application field. However, investigations are required to test if resistances of bacteria are developed upon exposure and if accumulation of dead bacteria on the coated surface will lead to reduction of its antimicrobial activity over a long period of time.

\section{Quorum Sensing Modulating Coating}

A different approach to prevent biofilm formation involves the inhibition of the cell-to-cell communication pathway of bacteria, known as quorum sensing (QS). ${ }^{[41-47]}$ Bacteria have evolved QS as a fascinating communication system to detect their local population density and coordinate their gene expression. This system is mediated by the exchange of small signaling molecules, so-called autoinducers, ${ }^{[48]}$ which are secreted and released by the bacteria themselves. Various bacterial functions are controlled by QS including extracellular polymer production, surface attachment, sporulation and the secretion of virulence factors. Therefore, interfering with the QS system could inhibit biofilm development. This idea of preparing antibiofilm surfaces that inhibit the QS communication pathway was inspired by nature. For instance, Delisea pulchra, a native red algae from southeastern Australia, stores anti-QS substances in vesicles situated on the surface of the alga to inhibit bacterial colonization. The secreted active compounds consist of a range of halogenated furanones called fimbrolides.[49] Several synthetic methods have been investigated to immobilize furanones on polymer materials to inhibit biofilm formation. ${ }^{[50,51]}$ However, such furanones were also shown to possess cytotoxic and mutagenic properties, thereby limiting their practical applications. ${ }^{[52,53]}$ Alternative strategies based on the molecular interference with QS pathways have been explored to influence the bacterial functions in order to inhibit biofilm formation. ${ }^{[54]}$ We have been particularly interested in Gram-negative bacteria, as their QS system is mostly mediated by the exchange of $N$-acyl-L-homoserine lactones (AHLs). ${ }^{[55-57]}$ Using an analogous strategy to our previous approach, various hybrids bearing an AHL moiety as recognition pattern for the bacteria and different anchor groups for the immobilization of QS modulators directly onto $\mathrm{TiO}$, surfaces were designed and synthesized. [39] These two fragments were connected by alkyl linkers with various lengths. Preliminary results with the AHL biosensor strain $C$. violaceum $\mathrm{CV026}{ }^{[58]}$ showed good activity of all the hybrids bearing a $\mathrm{C}_{12}$ alkyl linker. Interestingly, the anchor group had no impact on the activity. Therefore, further studies were initiated using the nitro-dopamine derivative due to the ease of accessibility, strong binding properties towards metal oxides, and stability towards oxidation (Fig. 4).

A modified dip-and-rinse procedure was applied for the immobilization of this hybrid onto $\mathrm{TiO}_{2}$ beads with an average diameter of $1 \mu \mathrm{m}$. The immobilized modulators proved to be the most sensitive for the GFP-based biosensor P. putida F117 (pAS-C8), ${ }^{[59]}$ having similar activity as the natural agonist $N$-octanoyl-L-homoserine lactone $\left(\mathrm{C}_{8}\right.$-AHL, Fig. 4). The biological activity could be preserved even after extensive washing of the beads up to ten times with water. The use of the beads was especially advantageous, as the location of the activated bacteria could be easily observed via fluorescence microscopy. Induction of QS was observed in the entire population and not only at the surface interface (Fig. 5a and 5b), comparable with the positive control using the free natural agonist (Fig. 5c and 5d). On the other hand, no GFP fluorescence could be observed in the absence of a modulator in the negative control (Fig. 5e and 5f). The mode of action was determined by performing dialysis assays using cellulose ester membranes. While the beads are retained in

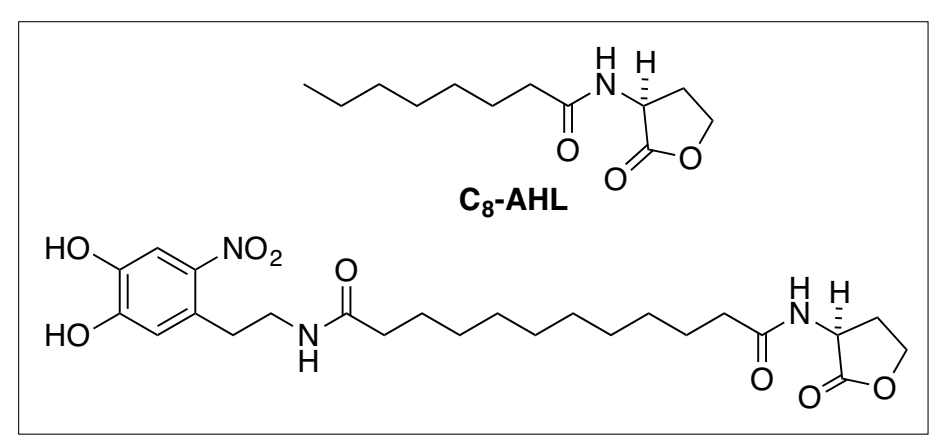

Fig. 4. Nitrodopamine-containing quorum sensing modulating coating agent and the natural agonist $\mathrm{C}_{8}-\mathrm{AHL}$.

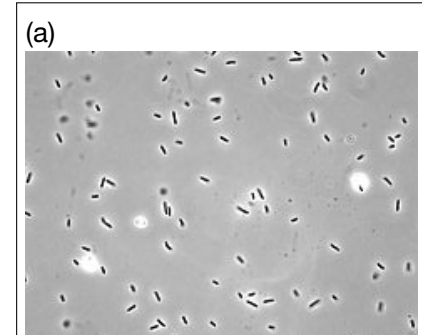

(b)

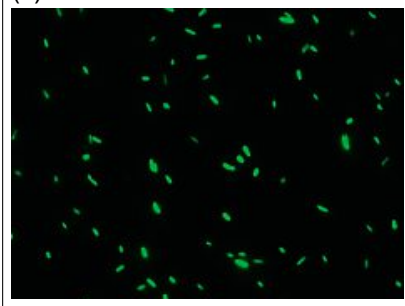

(c)

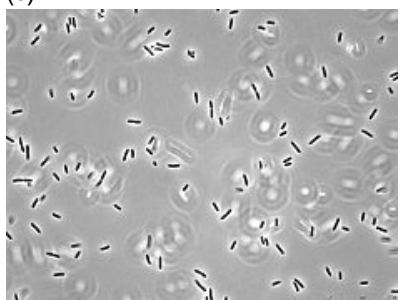

(d)

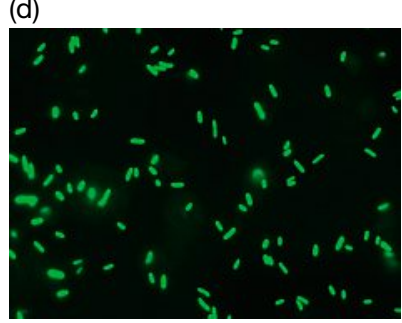

(e)

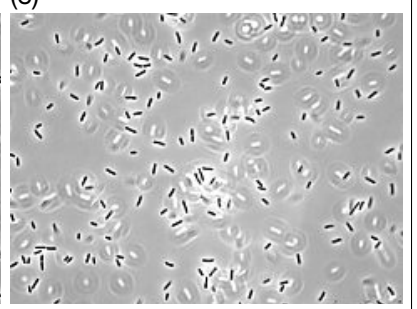

(f)

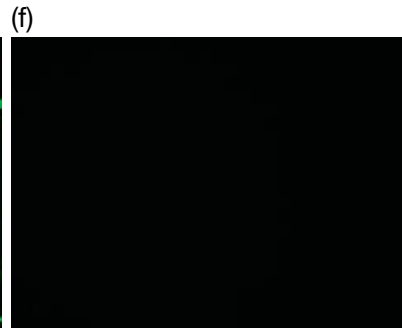

Fig. 5. Phase contrast (a) and GFP fluorescence (b) of the sensor incubated with the functionalized beads. Phase contrast (c) and GFP fluorescence (d) of the sensor incubated with the natural agonist $\mathrm{C}_{8}-\mathrm{AHL}$ as a positive control. Phase contrast (e) and GFP fluorescence ( $f$ ) of the sensor as a negative control. Fig. 5 reproduced from ref. [39] with permission of The Royal Society of Chemistry. 
dialysis bags during this assay, released hybrids can diffuse into the surrounding medium and modulate QS in the biosensor. Fluorescence was observed in the reporter strain situated on the outside of the dialysis bags, showing that AHL mimics are released from the beads. The observed release was steady and a linear increase of activity after overnight incubation was monitored. The mechanism of release from the surface is not yet fully understood and is currently under investigation.

\section{Conclusion}

In conclusion, the preparation of bioactive metal oxide surfaces can be easily achieved through an operationally simple dip-and-rinse procedure using dopaminebased anchoring moieties. This approach was successfully applied to the functionalization of $\mathrm{TiO}_{2}$ surfaces using different bifunctional coating agents. The combination of the anachelin chromophore and nitro-dopamine with PEG afforded an antifouling agent, which could successfully be immobilized and thereby render the coated surface repellent against proteins and microorganisms. This method was expanded by the covalent linkage of vancomycin to PEG. The resulting surfaces showed antibacterial properties, which could be preserved even after washing. Last, a quorum sensing modulating coating agent could be adsorbed on $\mathrm{TiO}_{2}$ beads. These beads were able to induce quorum sensing in the entire bacterial population, which was shown to occur upon slow release of the hybrids. Again, the biological activity could be preserved upon washing of the beads up to ten times without significant observable decrease. Such surfaces could not only find applications in medicine, but also in agriculture and material sciences.

\section{Acknowledgements}

We are indebted to our collaborators and friends (Prof. M. Textor/ETH, Dr. S. Zürcher/SurfaceSolutions, Dr. S. Tosatti/ SurfaceSolutions) for many stimulating discussions as well as our former coworkers (Dr. Y. Bethuel, D. Wäckerlin, Dr. S. Saxer, Dr. B. Malisova and Dr. J.-Y. Wach) for their contributions as documented in the original references. We thank the Swiss National Science Foundation (200021-144028, PE0022-117136, $31003 \mathrm{~A}-122013$ and 143773) for financial support. Part of this work is supported by the NCCR 'Chemical Biology'. The authors thank Dr. Christof Sparr, Dr. Erika Crane and Johannes Hoecker for proofreading the manuscript.

Received: February 28, 2013

[1] J. L. Del Pozo, R. Patel, N. Engl. J. Med. 2009, $361,787$.

[2] W. Zimmerli, A. Trampuz, P. E. Ochsner, $N$. Engl. J. Med. 2004, 351, 1645.

[3] R. O. Darouiche, Int. J. Artif. Organ 2007, 30, 820.

[4] C. Muto, C. Herbert, E. Harrison, J. R. Edwards, T. Horan, M. Andrus, J. A. Jernigan, P. K. Kutty, MMWR 2005, 54, 1013

[5] J. M. Higashi, I.-W. Wang, D. M. Shlaes, J. M. Anderson, R. E. Marchant, J. Biomed. Mater. Res. 1998, 39, 341.

[6] K. M. Cunnion, J. C. Lee, M. M. Frank, Infect. Immun. 2001, 69, 6796.

[7] T.-F. C. Mah, G. A. O'Toole, TRENDS Microbiol. 2001, 9, 34.

[8] H. S. Gold, R. C. Moellering, N. Engl. J. Med. 1996, 335, 1445 .

[9] J. P. Burke, N. Engl. J. Med. 2003, 348, 651.

[10] J. W. Costerton, Science 1999, 284, 1318.

[11] C. Walsh, Nature 2000, 406, 775.

[12] A. S. Lynch, G. T. Robertson, Annu. Rev. Med. 2008, 59,415 .

[13] S. Saint, C. P. Kowalski, S. R. Kaufman, T. P. Hofer, C. A. Kauffman, R. N. Olmsted, J. Forman, J. Banaszak-Holl, L. Damschroder, S. L. Krein, Clin. Infect. Dis. 2008, 46, 243.

[14] L. Braydich-Stolle, Toxicol. Sci. 2005, 88, 412.

[15] J. H. Waite, M. L. Tanzer, Science 1981, 212, 1038.

[16] C. R. Rice, M. D. Ward, M. K. Nazeeruddin, M. Grätzel, New J. Chem. 2000, 24, 651.

[17] J. L. Dalsin, B.-H. Hu, B. P. Lee, P. B. Messersmith, J. Am. Chem. Soc. 2003, 125, 4253.

[18] X. Fan, L. Lin, J. L. Dalsin, P. B. Messersmith, J. Am. Chem. Soc. 2005, 127, 15843.

[19] H. Lee, N. F. Scherer, P. B. Messersmith, Proc. Natl. Acad. Sci. USA 2006, 103, 12999.

[20] J. L. Dalsin, P. B. Messersmith, Mater. Today 2005, 38 .

[21] Q. Ye, F. Zhou, W. Liu, Chem. Soc. Rev. 2011, 40,4244

[22] T. J. Deming, Curr. Opin. Chem. Biol. 1999, 3, 100.

[23] H. G. Silverman, F. F. Roberto, Mar. Biotechnol. 2007, 9, 661

[24] J. Sedó, J. Saiz-Poseu, F. Busqué, D. RuizMolina, Adv. Mater. 2013, 25, 653.

[25] B. Malisova, S. Tosatti, M. Textor, K. Gademann, S. Zürcher, Langmuir 2010, 26 , 4018.

[26] S. Zürcher, D. Wäckerlin, Y. Bethuel, B. Malisova, M. Textor, S. Tosatti, K. Gademann, J. Am. Chem. Soc. 2006, 128, 1064.

[27] J.-Y. Wach, B. Malisova, S. Bonazzi, S. Tosatti, M. Textor, S. Zürcher, K. Gademann, Chem. Eur. J. 2008, 14, 10579.

[28] J.-Y. Wach, S. Bonazzi, K. Gademann, Angew. Chem. Int. Ed. 2008, 47, 7123.
[29] K. N. Raymond, E. A. Dertz, S. S. Kim, Proc. Natl. Acad. Sci. USA 2003, 100, 3584.

[30] K. Gademann, Y. Bethuel, Org. Lett. 2004, 6, 4707.

[31] K. Gademann, Y. Bethuel, Angew. Chem. Int. Ed. 2004, 43, 3327.

[32] K. Gademann, Y. Bethuel, H. H. Locher, C. Hubschwerlen, J. Org. Chem. 2007, 72, 8361.

[33] K. Gademann, ChemBioChem 2005, 6, 913.

[34] K. Gademann, Chimia 2007, 61, 373.

[35] I. Banerjee, R. C. Pangule, R. S. Kane, $A d v$. Mater. 2011, 23, 690.

[36] R. L. C. Wang, H. J. Kreuzer, M. Grunze, J. Phys. Chem. B 1997, 101, 9767.

[37] K. Yoshimoto, M. Nishio, H. Sugasawa, Y. Nagasaki, J. Am. Chem. Soc. 2010, 132, 7982.

[38] R. Wehlauch, J. Hoecker, K. Gademann, ChemPlusChem 2012, 77, 1071.

[39] J. Gomes, A. Grunau, A. K. Lawrence, L. Eberl, K. Gademann, Chem. Commun. 2013, 49, 155.

[40] J. C. Tiller, Adv. Polym. Sci. 2011, 240, 193.

[41] C. Fuqua, S. C. Winans, E. P. Greenberg, Аппи. Rev. Microbiol. 1996, 50, 727.

[42] R. Mittal, S. Sharma, S. Chhibber, S. Aggarwal, V. Gupta, K. Harjai, FEMS Immun. Med. Microbiol. 2010, 58, 237.

[43] M. Juhas, L. Eberl, B. Tummler, Environ. Microbiol. 2005, 7, 459.

[44] B. L. Bassler, Cell 2002, 109, 421.

[45] B. L. Bassler, R. Losick, Cell 2006, 125, 237.

[46] S. P. Diggle, S. A. Crusz, M. Cámara, Curr. Biol. 2007, 17, R907.

[47] C. M. Waters, B. L. Bassler, Annu. Rev. Cell Dev. Biol. 2005, 21, 319 .

[48] M. Boyer, F. Wisniewski-Dyé, FEMS Microbiol. Ecol. 2009, 70, 1 .

[49] M. Manefield, R. de Nys, N. Kumar, R. Read, M. Givskov, P. Steinberg, S. Kjelleberg, Microbiology 1999, 145, 283.

[50] E. B. H. Hume, J. Baveja, B. Muir, T. L. Schubert, N. Kumar, S. Kjelleberg, H. J. Griesser, H. Thissen, R. Read, L. A. PooleWarren, K. Schindhelme, M. D. P. Willcox, Biomaterials 2004, 25, 5023.

[51] S. A. Al-Bataineh, L. G. Britcher, H. J. Griesser, Surf. Interface Anal. 2006, 38, 1512

[52] R. T. LaLonde, L. Bu, A. Henwood, J. Fiumano, L. Zhang, Chem. Res. Toxicol. 1997, 10, 1427.

[53] T. Janecki, E. Blaszczyk, K. Studzian, M. Rózalski, U. Krajewska, A. Janecka, J. Med. Chem. 2002, 45, 1142.

[54] V. Lazar, Anaerobe 2011, 17, 280.

[55] W. R. J. D. Galloway, J. T. Hodgkinson, S. D. Bowden, M. Welch, D. R. Spring, Chem. Rev. 2011, $111,28$.

[56] N. A. Whitehead, A. M. L. Barnard, H. Slater, N. J. L. Simpson, G. P. C. Salmond, FEMS Microbiol. Rev. 2001, 25, 365.

[57] Y. Deng, J. Wu, F. Tao, L.-H. Zhang, Chem. Rev. 2011, 111, 160.

[58] K. H. McClean, M. K. Winson, L. Fish, A. Taylor, S. R. Chhabra, M. Cámara, M. Daykin, J. H. Lamb, S. Swift, B. W. Bycroft, G. S. A. B. Stewart, P. Williams, Microbiology 1997, 143, 3703.

[59] A. Steidle, K. Sigl, R. Schuhegger, A. Ihring, M. Schmid, S. Gantner, M. Stoffels, K. Riedel, M. Givskov, A. Hartmann, C. Langebartels, L. Eberl, Appl. Environ. Microbiol. 2001, 67, 5761. 